\title{
Ischemic Cerebrovascular Accident
}

National Cancer Institute

\section{Source}

National Cancer Institute. Ischemic Cerebrovascular Accident. NCI Thesaurus. Code C95802.

An acute episode of focal cerebral, spinal, or retinal dysfunction caused by infarction of brain tissue. 